\title{
Effect of age and estrogen on biochemical markers of bone turnover in postmenopausal women: a population-based study from Nepal
}

This article was published in the following Dove Press journal:

International Journal of Women's Health

25 October 2017

Number of times this article has been viewed

\author{
Bashu Dev Pardhe \\ Sabala Pathak \\ Anjeela Bhetwal \\ Sumitra Ghimire \\ Shreena Shakya \\ Puspa Raj Khanal \\ Sujan Babu Marahatta
}

Department of Laboratory Medicine, Manmohan Memorial Institute of Health Sciences, Kathmandu, Nepal
Correspondence: Bashu Dev Pardhe Department of Laboratory Medicine, Manmohan Memorial Institute of Health Sciences, PO Box No I520I, Kathmandu, Nepal

Tel +977 | 403078 ।

Email bashudev.pardhe@mmihs.edu.np
Background: Osteoporosis, a common disease worldwide, is characterized by low bone mass and architectural deterioration of bone tissue, leading to enhanced bone fragility and increase in fracture risks. Both menopause and aging are related factors leading to greater risk of bone disease, particularly among postmenopausal women. Hence, the main purpose of this study was to investigate the differences in biochemical markers of bone turnover and to evaluate the association of hormones and age-related factors with biochemical markers between pre- and postmenopausal women.

Methods: A descriptive cross-sectional study was conducted over a period of 6 months among the female population of Dholahity community, Lalitpur, Nepal. A total of 496 healthy women were selected based on the questionnaire strategy. Among them, 244 were premenopausal and 252 were postmenopausal women. Different bone markers were evaluated as per the guideline provided by the reagent manufacturer, and hormonal assay, particularly estradiol level assessment, was performed by chemiluminescence immunoassay-based technique.

Results: A significant decrease in serum calcium level and estradiol level was observed in postmenopausal women as compared to premenopausal women, whereas a significant increase in serum phosphorus and alkaline phosphatase (ALP) levels was seen among postmenopausal $(p<0.001)$. Age was significantly correlated with bone markers (ALP and calcium) in postmenopausal group $(p<0.005)$, while there was no significant correlation in premenopausal group. In addition, there was significant positive correlation between calcium and estradiol in postmenopausal women, while ALP was negatively correlated with estradiol in that group. Further, no significant correlation was demonstrated between estradiol and bone markers in postmenopausal women in body mass index and age-adjusted partial correlation analysis.

Conclusion: Timely diagnosis of osteoporosis in women would be of significant benefit for effective care for required populations and help to minimize mortality rate and financial burden of our country.

Keywords: postmenopause, osteoporosis, bone markers, estradiol, Nepal

\section{Background}

Globally, osteoporosis is occurring at an alarming rate and is becoming a major health issue, particularly among postmenopausal women, and this leads to high morbidity and mortality. ${ }^{1}$ The disease is characterized by low bone mass and architectural deterioration of bone tissue, leading to enhanced bone fragility and a consequent increase in fracture risks. ${ }^{2,3}$ About 200 million people are suffering from this chronic metabolic disease worldwide. ${ }^{4}$ Female gender, body mass index (BMI), and lifestyle-related factors are the established contributors for increased osteoporosis. ${ }^{5}$ 
Age is also an important factor affecting bone metabolism. In childhood and teenage years, the formation of new bone is faster than the resorption of old bones. Bone formation outpaces resorption until peak bone mass is reached at around 30 years of age, after which bone resorption slowly begins to exceed bone formation, ${ }^{6}$ and the risk of osteoporotic fracture doubles within 7-8 years after the age of $50 .^{5}$

Menopause occurs when there is an imbalance between the rates of bone formation and resorption, and excessive resorption results in negative remodeling balance leading to osteoporosis and other metabolic bone disease. ${ }^{7}$ With the onset of menopause, there is rapid bone loss, believed to be approximately $2 \%-3 \%$ over the following $5-10$ years, and this is greatest in the early postmenopausal years. ${ }^{1}$ Hormonal changes that occur during the menopausal transition play a crucial role in the development of this disease. ${ }^{8}$ Among different hormones, testosterone and estrogen help maintain bone structure throughout life. Estrogen, the best stimulator of bone growth, is responsible for maintaining the bone mass in the female. Nevertheless, after the menopause, estrogen level decreases and poses a risk for bone disease among postmenopausal women. ${ }^{9}$

In Europe and America, about $30 \%$ of men and $40 \%$ of postmenopausal women are predicted to spend the remainder of their life suffering from osteoporosis. ${ }^{4}$ However, the rate of osteoporosis is far higher in Asian population, and it has been estimated that about $50 \%$ of the people will be victims of osteoporosis by $2050 .{ }^{10}$ Furthermore, this problem is more centered in populations residing in the rural areas, and a majority of population in Nepal live in such communities where people with osteoporosis remain undiagnosed. Specially in our country, $50 \%$ of the total population are women, and among them greater than $50 \%$ are elderly, ${ }^{11}$ and this is the group that is at high risk for osteoporosis.

Several studies, available to date, have documented the information of osteoporosis among postmenopausal women from various parts of the world. However, community-based evidences from Nepalese postmenopausal women are scarce in the literature. Therefore, in this study, we aimed to investigate the status of bone turnover and related diseases among high-risk postmenopausal women.

\section{Methods}

A descriptive cross-sectional study was conducted over a period of 6 months among the female population of Dholahity community, Lalitpur, Nepal. The selection of 496 healthy women was based on the questionnaire strategy. Among them, 244 were premenopausal and 252 were postmenopausal women. Information regarding the patient demography (age and sex), duration of menopause, age of menarche, history of hysterectomy, bone-related medication intake, and any hormonal therapy were collected and recorded in a clinical profile form.

About $5 \mathrm{~mL}$ of venous blood was collected from every woman for the estimation of biochemical parameters. Serum calcium, serum phosphorous, and serum alkaline phosphatase (ALP) levels were estimated to serve as biochemical markers of bone turnover. The standard methods for the assays were based on the guideline provided by the reagent manufacturer (Human Gm Bh, Germany) of HumaStar 300, a fully automated analyzer. The reference range for serum calcium was considered as $8.1-10.4 \mathrm{mg} / \mathrm{dL}$, serum phosphorous was $2.5-5.0 \mathrm{mg} / \mathrm{dL}$, and normal activity of serum ALP was 44-174 IU/L. A hormonal assay, particularly estradiol level assessment, in every individual was performed by chemiluminescence immunoassay-based technique using MAGLUMI 1000 plus in the Department of Laboratory Medicine, Manmohan Memorial Teaching Hospital. The normal range for estradiol was considered as $10-66 \mathrm{pg} / \mathrm{mL}$ in postmenopausal phase and $236-251 \mathrm{pg} / \mathrm{mL}$ in premenopausal phase as provided in the manufacturer's guidelines. The analytical sensitivity of the assay was less than $8 \mathrm{pg} / \mathrm{mL}$. Intra-assay coefficient of variation $(\mathrm{CV})$ was evaluated by the manufacturer in three different levels of control serum repeatedly measured 20 times in the same run, and $\mathrm{CV} \%$ was 8.20 for level $1(138.25 \pm 11.33 \mathrm{pg} / \mathrm{mL}), 4.82$ for level 2

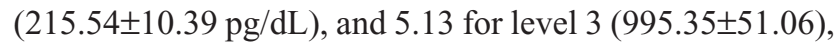
while interassay $\mathrm{CV}$ was evaluated by the manufacturer on three different batches of kits. Three different levels of control serum were repeatedly measured for 21 times and $\mathrm{CV} \%$ was 9.66 for level 1 (132.54 $\pm 12.80 \mathrm{pg} / \mathrm{mL})$, 9.11 for level 2 (205.78 $\pm 18.75 \mathrm{pg} / \mathrm{dL})$, and 7.95 for level 3 $(985.57 \pm 78.35)$.

\section{Inclusion and exclusion criteria}

Apparently healthy participants were included in the study. Written informed consent was taken from each individual, and individuals were grouped under pre- and postmenopausal based on the questionnaire results. Women who had amenorrhea due to hysterectomy or any other known causes, apart than natural causes, those with rheumatoid arthritis, those taking any hormone replacement therapy or on any bonerelated medications, those with history of diabetes mellitus, thyroid disorders, jaundice, and liver diseases, and those who were heavy smokers and/or alcoholic were excluded from the study. 


\section{Ethical approval}

Written approval (ref 006/072-073/MMIHS) was obtained from the institutional review committee of MMIHS after submitting and presenting the proposal to the committee.

\section{Data analysis}

Data were analyzed using SPSS version 20.0 (IBM Corp., Armonk, NY, USA) and Microsoft Excel 2013. Student's $t$-test was used to analyze the differences in biochemical markers of bone turnover between pre- and postmenopausal women. Likewise, Pearson correlation coefficient was used to evaluate the association of hormones and age-related factors with biochemical markers of bone turnover in postmenopausal women.

\section{Results}

Out of 496 healthy women residing in a community in Nepal, 244 were premenopausal with an average age of $26 \pm 7.5$ and the remaining 252 were postmenopausal with average age of $68 \pm 11.5$. The mean age of menarche was $12.90 \pm 1.15$, and mean age menopause was $47.02 \pm 4.44$ in the study population. A majority of the women were from the Brahmin community (26.2\%) followed by Newar and Mangolian (22.4\%), and the rest were from other ethnicities. About $70.9 \%$ of women had normal BMI, while $29.1 \%$ were obese, and the frequency of obesity was higher in the postmenopausal group than premenopausal group (Table 1).

In our study, we observed a significant decrease in serum calcium level and estradiol levels in postmenopausal women as compared to premenopausal women $(p<0.001)$. However, there was a significant increase in serum phosphorus and ALP levels in postmenopausal women when compared to premenopausal women $(p<0.001)$ (Table 2$)$.

Table I Frequency distribution of demographic characteristics of the total study population

\begin{tabular}{llll}
\hline Characteristics & $\begin{array}{l}\text { Premenopausal } \\
(\mathbf{N}=\mathbf{2 4 4})\end{array}$ & $\begin{array}{l}\text { Postmenopausal } \\
(\mathbf{N}=\mathbf{2 5 2})\end{array}$ & Total \\
\hline BMI status & & & \\
$\quad \begin{array}{l}\text { Normal weight } \\
\text { Obese }\end{array}$ & $198(39.9)$ & $154(3 \mathrm{I})$ & $352(70.9)$ \\
$\begin{array}{l}\text { Ethnicity } \\
\text { Brahmin }\end{array}$ & $92(9.3)$ & $98(19.8)$ & $144(29.1)$ \\
Newar & $60(12.1)$ & $88(17.7)$ & $180(26.2)$ \\
Mangolian & $56(11.3)$ & $52(10.5)$ & $112(22.6)$ \\
Other & $36(7.3)$ & $56(11.3)$ & $112(22.6)$ \\
\hline
\end{tabular}

Note: Data presented as $\mathrm{n}(\%)$.

Abbreviation: BMl, body mass index.
Table 2 Mean comparison of bone markers in pre- and postmenopausal women

\begin{tabular}{llll}
\hline Characteristics & $\begin{array}{l}\text { Premenopause } \\
\text { (mean } \pm \text { SD) }\end{array}$ & $\begin{array}{l}\text { Postmenopause } \\
(\text { mean } \pm \text { SD) }\end{array}$ & p-value \\
\hline BMl $\left(\mathrm{kg} / \mathrm{m}^{2}\right)$ & $22.1 \pm 4.0$ & $24.4 \pm 4.4$ & $<0.05$ \\
$\begin{array}{l}\text { Serum calcium } \\
\text { (mg/dL) }\end{array}$ & $8.3 \pm 0.9$ & $7.7 \pm 1.0$ & $<0.001$ \\
$\begin{array}{l}\text { Serum phosphorus } \\
\text { (mg/dL) }\end{array}$ & $3.4 \pm 0.6$ & $3.7 \pm 0.5$ & $<0.001$ \\
$\begin{array}{l}\text { Serum ALP }(\mathrm{U} / \mathrm{L}) \\
\text { Serum estradiol }\end{array}$ & $198.8 \pm 53.0$ & $259 \pm 91.0$ & $<0.00 \mathrm{I}$ \\
(pg/mL) & $176.28 \pm 73.63$ & $32.48 \pm 13.02$ & $<0.001$ \\
\hline
\end{tabular}

Abbreviations: ALP, alkaline phosphatase; BMI, body mass index.

There was significant decrease in mean serum calcium and estradiol levels in postmenopausal-late group (group II) compared to postmenopausal-early group (group I), while ALP level was significantly increased in group II postmenopausal women $(p<0.05)$. Among the postmenopausal women, the level of estradiol was significantly decreased in group II than in group I women $(p<0.01)$. Serum phosphorus was significantly decreased $(p<0.001)$ in the obese group compared to the normal body weight group. There was neither a significant increase in the serum calcium level nor a decrease in ALP level among obese postmenopausal women, compared to postmenopausal women with normal BMI. Above all, the level of estradiol was significantly high and level of phosphorous was significantly low $(p<0.001)$ in obese women than in those with normal weight in the postmenopausal group (Table 3 ).

In addition, there was a decrease in serum calcium level with increasing age. No significant negative correlation of age with calcium was observed among premenopausal women, but a significant negative correlation was observed between age and calcium in postmenopausal women ( $p=0.002)$. Similarly, age was not negatively correlated with phosphorous in the premenopausal group, and neither was it positively correlated in postmenopausal group. Among the premenopausal women, there was a nonsignificant negative correlation between age and ALP, but in postmenopausal women age was positively correlated with ALP $(p=0.026)$ (Table 4).

The regression analysis showed a strong negative correlation between calcium and estradiol levels in premenopausal women, while their correlation with postmenopausal women was positive (Figure 1). The level of phosphorous was significantly positively correlated with estradiol in premenopausal women, while a nonsignificant negative correlation was observed in the postmenopausal group (Figure 2). Lastly, 
Table 3 Relationship between demographic and clinical characteristics with different bone markers in postmenopausal women

\begin{tabular}{|c|c|c|c|c|c|c|c|c|}
\hline \multirow[t]{2}{*}{ Variables } & \multicolumn{2}{|c|}{ Calcium (mg/dL) } & \multicolumn{2}{|c|}{ Phosphorus (mg/dL) } & \multicolumn{2}{|l|}{ ALP (IU/L) } & \multicolumn{2}{|c|}{ Estradiol (pg/mL) } \\
\hline & Mean \pm SD & $p$-value & Mean \pm SD & $p$-value & Mean \pm SD & $p$-value & Mean \pm SD & $p$-value \\
\hline \multicolumn{9}{|l|}{ Menopause status } \\
\hline Group I & $8.1 \pm 0.4$ & 0.012 & $3.7 \pm 0.6$ & 0.95 & $224.9 \pm 83.2$ & 0.045 & $45.9 \pm 13.1$ & $<0.001$ \\
\hline Group II & $7.6 \pm 0.9$ & & $3.7 \pm 0.5$ & & $266.8 \pm 91.8$ & & $29.6 \pm 11.2$ & \\
\hline \multicolumn{9}{|l|}{ Body weight status } \\
\hline Normal weight & $7.5 \pm 0.9$ & 0.11 & $3.8 \pm 0.5$ & $<\mathbf{0 . 0 0 I}$ & $262.5 \pm 84.1$ & 0.69 & $30.4 \pm 12.3$ & 0.028 \\
\hline Obese & $7.8 \pm 0.9$ & & $3.5 \pm 0.5$ & & $254.6 \pm 101.9$ & & $35.6 \pm 13.3$ & \\
\hline \multicolumn{9}{|l|}{ Ethnicity } \\
\hline Brahmins & $7.7 \pm 0.8$ & 0.04 & $3.7 \pm 0.5$ & 0.9 & $249.8 \pm I 15.6$ & 0.3 & $37.5 \pm 13.3$ & $<0.001$ \\
\hline Janajati & $8.6 \pm 0.9$ & & $3.7 \pm 0.5$ & & $264.5 \pm 75.6$ & & $29.7 \pm 12.2$ & \\
\hline
\end{tabular}

Notes: Group I: duration of menopause $\leq 5$ years, Group II: duration of menopause $>6$ years. Bold represents statistically significant values $(p<0.05)$.

Abbreviation: ALP, alkaline phosphatase.

ALP was significantly positively correlated with estradiol among premenopausal women, whereas in postmenopausal women ALP was negatively correlated with no statistical significance (Figure 3). Further, an age- and BMI-adjusted partial correlation between estradiol level and bone markers was performed. In the analysis, all the bone markers were correlated at nonsignificant levels in postmenopausal women, with calcium and ALP levels being significantly correlated with estradiol level in previous nonadjusted analysis. ALP and calcium levels were significantly correlated with estradiol levels in premenopausal women in adjusted analysis, whereas all bone markers were significantly correlated in nonadjusted analysis in the same group (Table 5).

\section{Discussion}

The risk factor that was most highly associated with osteoporosis in postmenopausal women was considered as estrogen deficiency. In addition, age-related factors also contribute to the risk of osteoporotic fracture. ${ }^{12}$ Osteoporosis in postmenopausal women can remain asymptomatic for a long time, with the only indication being changes in biochemical markers of bone turnover. ${ }^{13}$ In Nepal, women make up more than 50\% of the population, and among this most of the population is over the age of $50 .{ }^{11}$ Specially, this group of population belongs to postmenopause and passes their retired life with

Table 4 Correlation of age with bone markers in pre- and postmenopausal women

\begin{tabular}{llllll}
\hline \multirow{2}{*}{$\begin{array}{l}\text { Bone } \\
\text { markers }\end{array}$} & \multicolumn{2}{l}{ Premenopause } & & \multicolumn{2}{l}{ Postmenopause } \\
\cline { 2 - 3 } & $\boldsymbol{r}$-value & $\boldsymbol{p}$-value & & $\boldsymbol{r}$-value & $\boldsymbol{p}$-value \\
\hline ALP & -0.053 & 0.561 & & $\mathbf{0 . 0 1 9 8}$ & 0.026 \\
Calcium & -0.060 & 0.513 & & $-\mathbf{0 . 2 7 9}$ & 0.002 \\
Phosphorus & -0.130 & 0.152 & & 0.059 & 0.514 \\
\hline
\end{tabular}

Note: Bold represents statistically significant values $(p<0.05)$.

Abbreviation: ALP, alkaline phosphatase. lack of physical activities and faced with poor nutrition in our economically poor country. This suggests that most of the Nepalese women are probably at risk of developing bonerelated disorders, which is a matter of concern. Therefore, this necessitates the incessant endeavors to investigate the quality of bone in postmenopausal women.

In this study, the number of obese women was higher in the postmenopausal group compared to the premenopausal women. This may be due to the deteriorated lipid metabolism resulting from the reduced effect of estrogen in postmenopausal women. ${ }^{14}$

Postmenopausal osteoporosis is triggered by the reduction of the effect of estrogen on bone, and this leads to a sharp acceleration of bone turnover with an imbalance toward excessive osteoclastic activity. ${ }^{15}$ Body mass density (BMD) and biochemical parameters estimation are the most common and easiest tools for estimation of osteoclastic activity. Measurement of degree of mineralization, hydroxyapetite crystal size, connectivity of trabucule, and bone microdamage are difficult, ${ }^{5}$ or even impossible in diagnosis and prognosis of osteoporosis in our country. Thus, monitoring of biochemical bone turnover markers are the focus area of our study. The mean value of serum calcium was significantly decreased $(p<0.05)$, while phosphorus and ALP levels were significantly increased $(p<0.05)$ in postmenopausal women when compared to premenopausal women. Similar studies were already conducted by Akshya Lekhi et $\mathrm{al}^{13}$ from the western part of Nepal and Bhattarai et $\mathrm{al}^{7}$ from the middle part of our country. Their observed patterns for calcium and ALP levels were similar to our study, and both reported a significant reduction in calcium level but significant upsurge in serum ALP level in postmenopausal women as compared to premenopausal women. ${ }^{13}$ Although the results were similar to our study, these hospital-based studies contrasted with this 

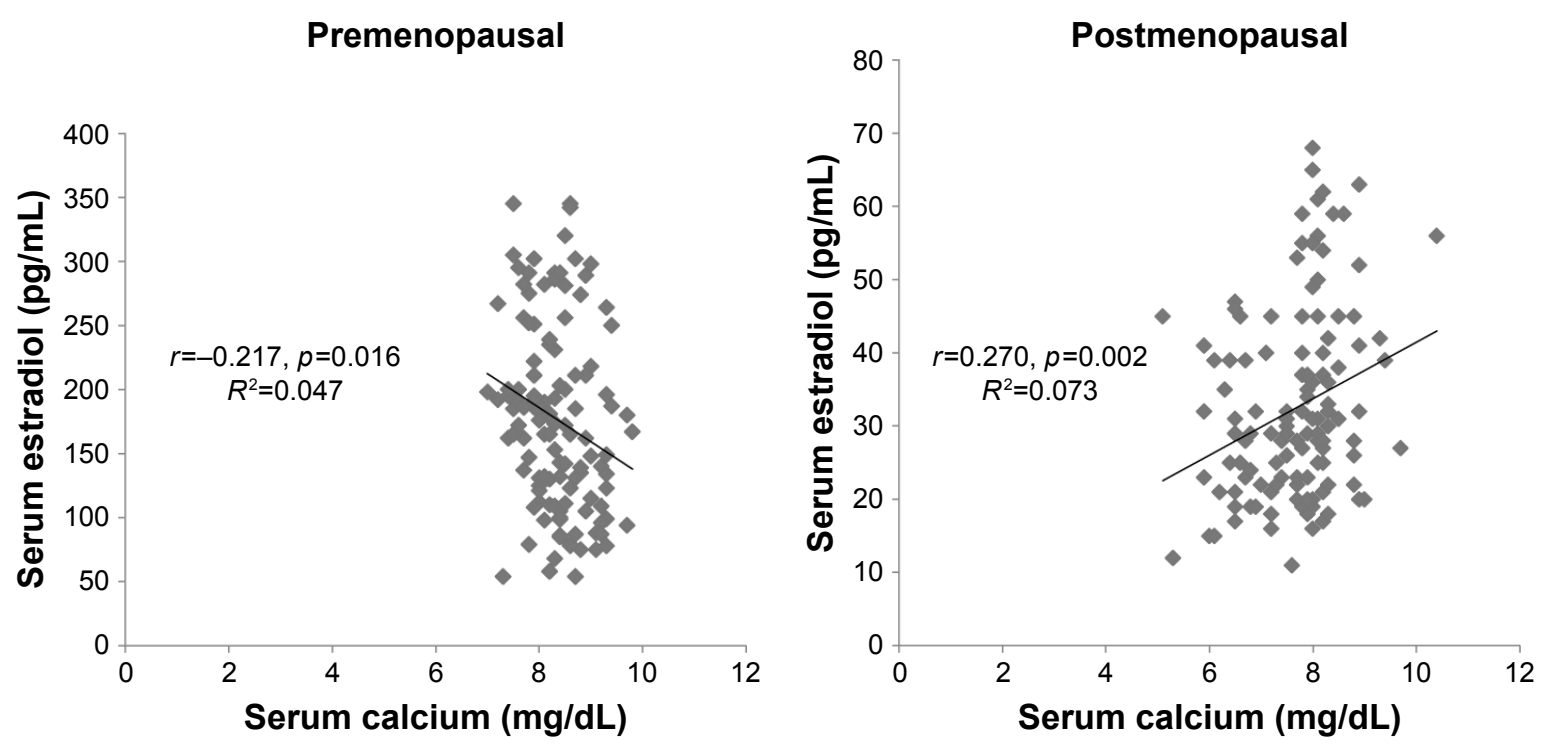

Figure I Correlation between serum estradiol and serum calcium in pre- and postmenopausal women.

study as ours was a community-based one covering only the healthy population. This may help to exclude the confounding factors related with bone turnover. Similar to the results of this study, an almost identical trend of biochemical changes in bone turnover markers was reported from different parts of the globe. ${ }^{2,4,5,16}$ In contrast to these findings, some studies also showed no significant changes in serum phosphorus and ALP levels in pre- and postmenopausal women. Onyeukwu et $\mathrm{al}^{17}$ illustrated that there was a significant decrease in serum calcium level in postmenopausal women as compared to premenopausal women, but there was no significant difference in serum phosphorus and ALP levels among these groups. This may be due to the decrease of estrogen which causes bone resorption in postmenopausal women, preventing the absorption and utilization of bone calcium causing the risk of osteoporosis. ${ }^{18}$ In general, it has been reported that women lose about $1 \%$ of their bone density per year during and after menopause. ${ }^{19}$

Hormonal influence in the reduction of BMD is clearly illustrated as being due to rapid bone resorption after the last menses. Bone loss reaches a peak at 3-4 years after onset of menopause, then progressively declines for a few years, and finally bone loss per year remains at around $1 \%$ to $1.5 \%{ }^{5}$ The Stages of Reproductive Ageing Workshop +10 system
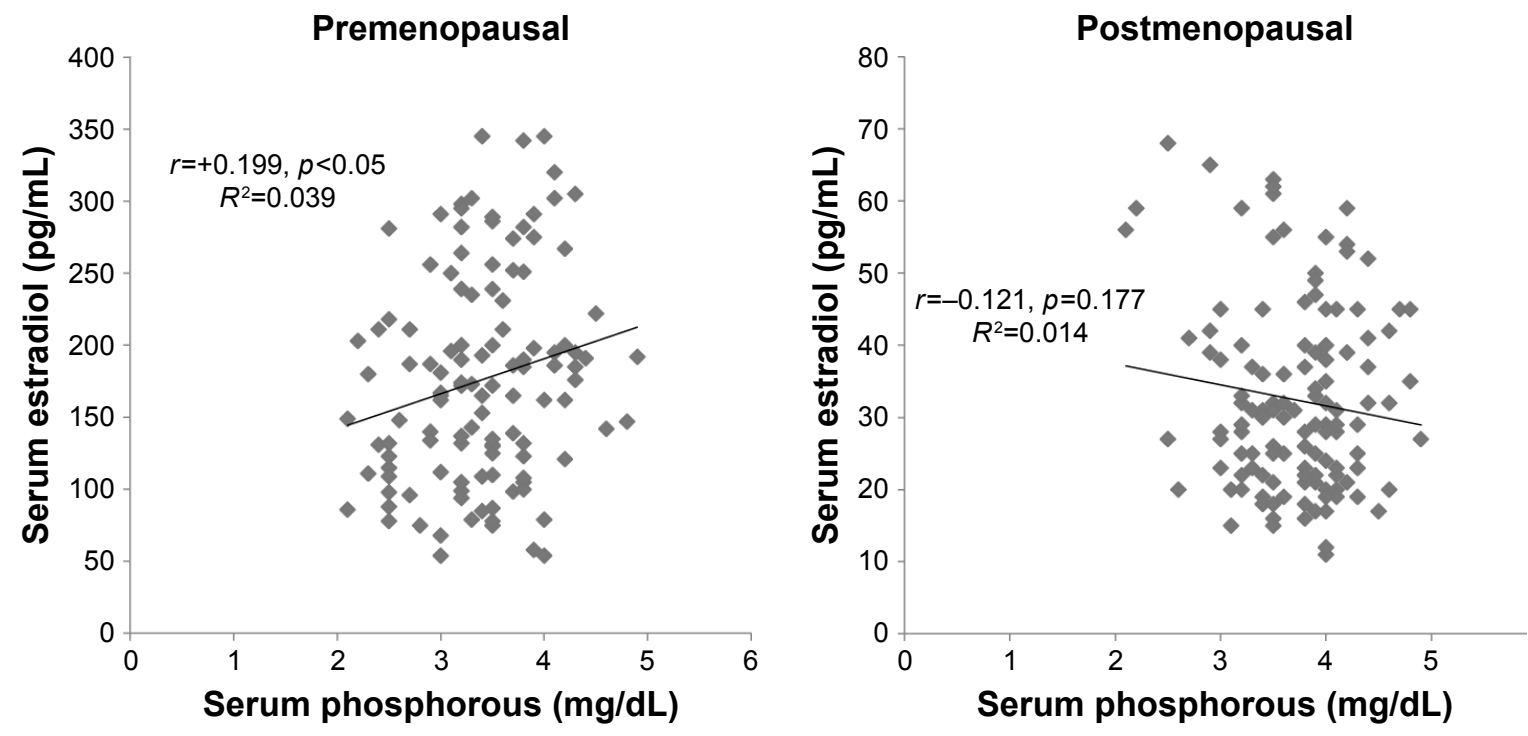

Figure 2 Correlation between serum estradiol and serum phosphorous in pre- and postmenopausal women. 

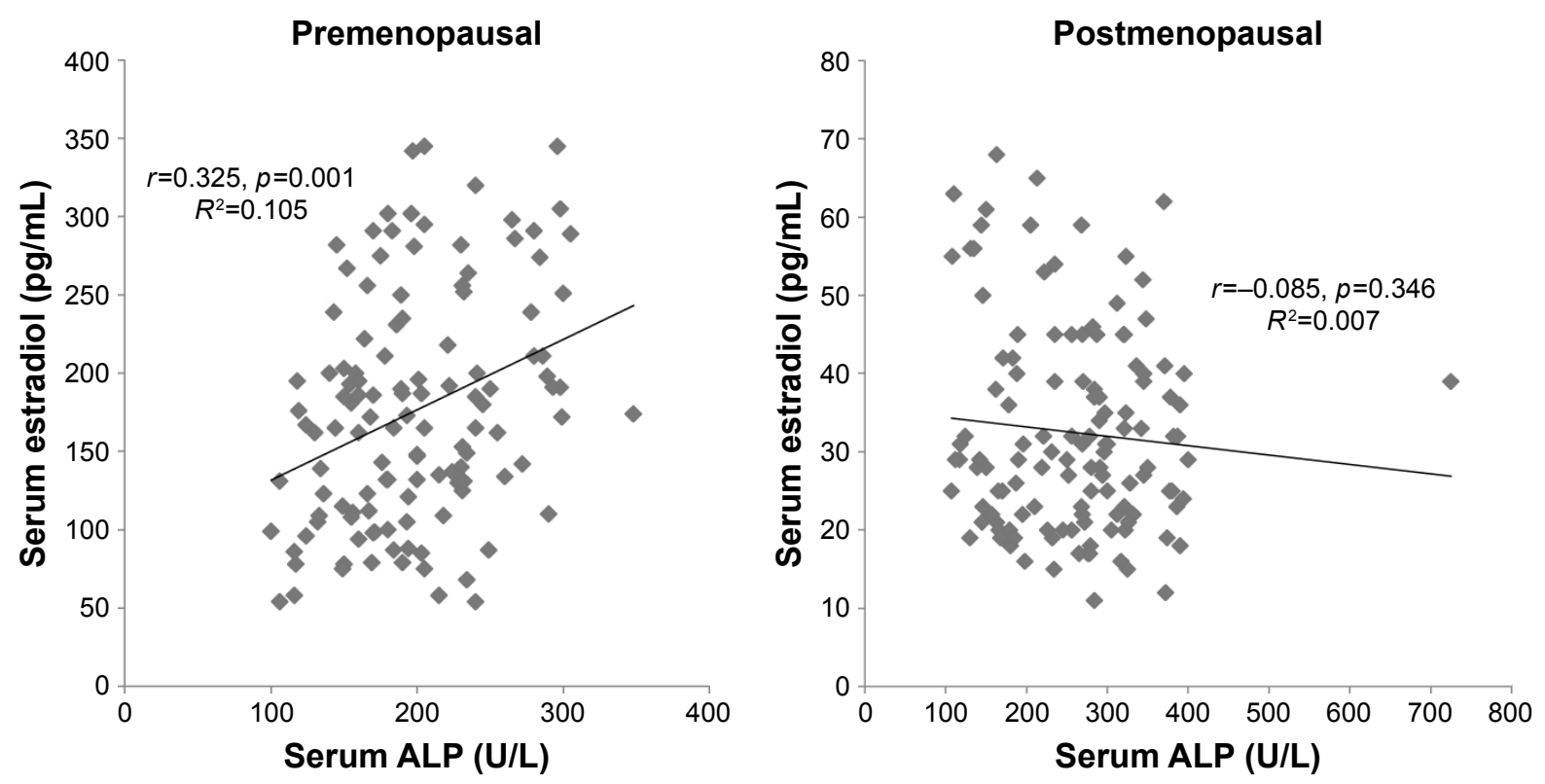

Figure 3 Correlation between serum estradiol and serum ALP in pre- and postmenopausal women. Abbreviation: ALP, alkaline phosphatase.

is used to assess reproductive aging through postmenopause regardless of age, demographic characteristics, BMI, and lifestyle intervention. Harlow et $\mathrm{al}^{20}$ define a period of 5-6 years of menopause as early menopause and of more than 5 years of menopause as postmenopause. The present study showed that the serum calcium level was significantly decreased and ALP levels were significantly high in the women during their early postmenopausal period when compared to the late postmenopausal period (between group I and group II). A similar result was also found in a study performed by Indumati et $\mathrm{al},{ }^{1}$ which shows that the bone mass continues to decline with age but at a slower rate during late postmenopause than during early postmenopause. ${ }^{21}$ This may be the result of the inhibitory effects of estrogen on bone turnover rate, which is dependent on age and BMI. ${ }^{16}$ There was also a significant decrease in the serum estradiol level among the late postmenopausal group compared to that among early postmenopausal group. The menopausal transition is associated with significant hormonal changes, most importantly a decline of estradiol

Table $5 \mathrm{BMI}$ and age adjusted partial correlation of estradiol with bone markers in pre- and postmenopausal women

\begin{tabular}{llllll}
\hline Bone & \multicolumn{2}{l}{ Premenopause } & & \multicolumn{2}{l}{ Postmenopause } \\
\cline { 2 - 3 } \cline { 5 - 6 } markers & r-value & p-value & & r-value & P-value \\
\hline ALP & $\mathbf{0 . 3 3 8}$ & 0.00 & & 0.057 & 0.528 \\
Calcium & $-\mathbf{0 . 2 9 8}$ & 0.001 & & 0.111 & 0.220 \\
Phosphorus & 0.164 & 0.073 & & -0.880 & 0.330 \\
\hline
\end{tabular}

Note: Bold represents statistically significant values $(p<0.05)$. Abbreviation: ALP, alkaline phosphatase. levels by about $60 \%$. In contrast, some researchers have reported that there was no significant change in calcium, phosphorus, and ALP levels between the early and late postmenopausal periods. ${ }^{17}$ This type of result may be caused due to the difference in study population and geographical variations.

Similar to our study results, various other studies have shown significant decrease $(p<0.05)$ in the serum estradiol level in the postmenopausal group as compared to that in the premenopausal group. ${ }^{22}$ After menopause, the ovaries cease to produce significant amounts of estradiol; therefore, symptoms and diseases associated with estradiol deficiency are of more importance to women's health. ${ }^{22}$ Altogether, estradiol level decreases from 7 to 10 -fold between pre- and postmenopause. ${ }^{14}$ Ashuma et $\mathrm{al}^{23}$ reported that aging and menopause lead to a decline in estradiol and progesterone production, which has been implicated in decreased calcium levels in postmenopausal women.

After the adjustment of the risk factors associated with bone loss, including adjustment for rheumatoid arthritis, alcohol and tobacco intake, and glucocorticoid therapy, estradiol level was significantly positively correlated with the serum calcium level (bone loss) in postmenopausal women $(p<0.05)$. But after the adjustment of BMI and age, the decrease in bone loss (serum calcium) was not correlated at a significant level. This explains that with increase in age and after menopause, there is the rapid decrease in calcium level along with estradiol level. Recent approaches from different 
studies explain the potent role of estrogen in the regulation of calcium and phosphorous. This estrogen-dependent calcium regulation mechanism suggests an important mechanism of pathogenesis in both postmenopausal and age-related osteoporosis. ${ }^{24}$ One study compared the equal role of estrogen in regulation of calcium and phosphorous in the kidney to the well recognized effect of PTH in elderly women. ${ }^{25}$ After menopause, there is reduction in estrogen production by the ovaries. This directly affects the bone status in that group of the population. Thus, calcium supplementation can reduce the bone loss in postmenopausal women, who are well characterized by estrogen deficiency and imbalanced calcium interaction mechanism. ${ }^{25}$

There was a positive significant correlation of ALP with estradiol in premenopausal women, while a negative correlation was observed for postmenopausal women in the study, and after the adjustment for age and BMI ALP was not found to be strongly associated with estradiol after menopause. Although ALP is a well-established marker of bone diseases, unfortunately it is not specific only for bone. Bone-specific ALP (BAP) measurement is worth in order to differentiate liver disease from osteoporotic activity. ${ }^{26}$

Bone mass decreases with aging, and it is now well established that a low bone mass is the main determinant of all osteoporotic fractures. ${ }^{27}$ The prevalence of osteoporosis increases with age for all sites, and according to the World Health Organization definition up to $70 \%$ of women over the age 80 years have osteoporosis. ${ }^{1}$ In our study, bone turnover was positively associated with age in both pre- and postmenopausal groups. With regard to the biochemical markers of bone turnover, calcium was significantly negatively correlated while ALP was significantly positively correlated with age in postmenopausal women. $(p<0.005)$ This indication clearly demonstrates progressive bone loss with an increase in age. The age-related factors of bone loss in postmenopausal women may be due to inadequate level of vitamin D and progressive increase in parathyroid hormone with increasing age. ${ }^{12,28}$ Inadequate level of vitamin $\mathrm{D}$ is the most common reason for women with osteoporosis, and progressive deficiency of this hormone may lead to secondary hyperparathyroidism. ${ }^{28}$ Haugen et $\mathrm{al}^{29}$ also reported high prevalence of vitamin D insufficiency (59.8\%) and deficiency $(14.0 \%)$ in young women from our country. Hence, estimation of vitamin D deficiency/insufficiency becomes mandatory before reporting bone status in young as well as postmenopausal women.

This illustrates a high risk of having fractures in postmenopausal women since there is increased bone loss with the increasing age, and is more common in females as a result of hormonal changes. Our study approach showed age as more relevant factor than estradiol level for increase in bone turnover in postmenopausal women. The evaluation of vitamin D status and its association with increased bone turnover is a topic for further study in our population. This singlecommunity-centered cross-sectional study, however, was limited with regard to the evaluation of all additional potential etiologies of osteoporosis in postmenopausal women.

\section{Conclusion}

This study shows that the assessment of hormone and biochemical markers, which can be easily performed and are convenient for repeated evaluation, are advantageous to observe bone turnover in post menopausal women. These types of community-based studies should be conducted in a larger scale at the national level for setting development policies and statements to guide the diagnosis, treatment, and prognosis of osteoporosis in postmenopausal women. Timely diagnosis of osteoporosis in women would be of significant benefit for the effective care for required populations and help to minimize mortality rate and financial burden in Nepal. Additional points

\section{Availability of data and materials}

All the data generated during this study are presented in this paper. The primary raw data will be made available to the interested researchers by the corresponding author of this article if requested.

\section{Acknowledgments}

We thank all the participants, management officials, and laboratory staffs of MMTHS and MMIHS for making this study possible.

\section{Author contributions}

BDP and SP conceived the design of the study, reviewed literature, performed necessary interventions including laboratory investigations, and analyzed the data. $\mathrm{SP}, \mathrm{SG}, \mathrm{AB}, \mathrm{SS}$, and PRK participated in community data collection, laboratory procedure, and data analysis. BDP and SBM prepared the manuscript. All authors contributed toward data analysis, drafting and critically revising the paper and agree to be accountable for all aspects of the work. All authors read the final version of manuscript and approved it for submission.

\section{Disclosure}

The authors report no conflicts of interest in this work. 


\section{References}

1. Indumati V, Patil VS, Jailkhani R. Hospital based preliminary study on osteoporosis in postmenopausal women. Indian J Clin Biochem. 2007; 22(2):96-100.

2. Garnero P, Delmas PD. 4 Bone markers. Baillière's Clin Rheumatol. 1997;11(3):517-537.

3. Lanham-New SA. Importance of calcium, vitamin D and vitamin $\mathrm{K}$ for osteoporosis prevention and treatment. Proc Nutr Soc. 2008;67(2): 163-176.

4. Sozen T, Ozisik L, Basaran NC. An overview and management of osteoporosis. Eur J Rheumatol. 2017;4(1):46-56.

5. Society NAM. NAMS Continuing medical education activity; Management of osteoporosis in postmenopausal women: 2010 position statement. Menopause. 2010;17(1):23-56.

6. Dean J. Oocyte-specific gene expression: roles in folliculogenesis, fertilization and early development. Cambridge, UK: Cambridge University Press; 2003.

7. Bhattarai T, Bhattacharya K, Chaudhuri P, Sengupta P. Correlation of common biochemical markers for bone turnover, serum calcium, and alkaline phosphatase in post-menopausal women. Malays J Med Sci. 2014;21(1):58.

8. Coxam V. Phyto-oestrogens and bone health. Proc Nutr Soc. 2008; 67(2):184-195.

9. Ross and Wilson AW, Grant A. The Musculoskeletal System. 10th ed. Elsevier Limited; 2006:384-387.

10. Thulkar J, Singh S, Sharma S, Thulkar T. Preventable risk factors for osteoporosis in postmenopausal women: Systematic review and metaanalysis. J Midlife Health. 2016;7(3):108.

11. Pardhe BD, Ghimire S, Shakya J, et al. Elevated cardiovascular risks among postmenopausal women: A community based case control study from Nepal. Biochem Res Int. 2017;2017:3824903.

12. Khosla S, Atkinson EJ, Melton LJ 3rd, Riggs BL. Effects of age and estrogen status on serum parathyroid hormone levels and biochemical markers of bone turnover in women: A Population-Based Study 1. J Clin Endocrinol Metab. 1997;82(5):1522-1527.

13. LeKhi A, LeKhi M, Sathian B, Mittal A. The role of biochemical markers in the early detection of osteoporosis in women: A comparative study from the Western Region of Nepal. J Clin Diagnos Res. 2012; 6(2):274-277.

14. Akahoshi M, Soda M, Nakashima E, et al. The effects of body mass index on age at menopause. Int J Obesity. 2002;26(7):961.

15. Clarke B. Normal bone anatomy and physiology. Clin J Am Soc Nephrol. 2008;3(3):04151206.
16. Deepthi S, Narayan G, Naidu J. Study of biochemical bone turnover markers in postmenopausal women leading to osteoporosis. Int J Appl Biol Pharm Technol. 2012;3(3):301-305.

17. Onyeukwu CU, Nsonwu AC. Biochemical bone turnover markers in postmenopausal women in Calabar municipality. Asian J Biochem. 2007;2(1):130-135.

18. Riggs BL. Age-related osteoporosis. Nutr Aging. 2012:207.

19. Kumari SN, Rosario SB, Gowda KD. Altered liver function and the status of calcium in postmenopausal women in and around mangalore. Al Ameen J Med Sci. 2010;3:115-119.

20. Harlow SD, Gass M, Hall JE, et al. Executive summary of the stages of reproductive aging workshop +10 : addressing the unfinished agenda of staging reproductive aging. J Clin Endocrinol Metab. 2012;97(4): 1159-1168.

21. Brandão CM, Lima MG, Silva AL, Silva GD, Guerra AA Jr, Acúrcio Fde A. Treatment of postmenopausal osteoporosis in women: a systematic review. Cad Saúde Pública. 2008;24(Suppl 4):s592-s606.

22. Kilim SR, Chandala SR. A comparative study of lipid profile and oestradiol in pre- and post-menopausal women. J Clin Diagnos Res. 2013;7(8):1596.

23. Ashuma S, Shashi S, Sachdeva S. Biochemical Markers of bone turnover: diagnostic and therapeutic principles. Osteoporosis. 2005; 332:305-311.

24. Prince R, Dick I. Oestrogen effects on calcium membrane transport: A new view of the inter-relationship between oestrogen deficiency and age-related osteoporosis. Osteoporosis Int. 1997;7(3):150-154.

25. Dick IM, Devine A, Beilby J, Prince RL. Effects of endogenous estrogen on renal calcium and phosphate handling in elderly women. Am J Physiol Endocrinol Metab. 2005;288(2):E430-E435.

26. Bikle DD. Biochemical markers in the assessment of bone disease. Am J Med. 1997;103(5):427-436.

27. Sajjanar DS, Sajjanar SL. Study of serum alkaline phosphatase, calcium and urinary hydroxyproline as bone biomarkers in postmenopausal women. Int J Basic Appl Med Sci. 2014;4(1):223-229. Available from: http://www.cibtech.org/jms.htm

28. Lips P, Hosking D, Lippuner K, et al. The prevalence of vitamin D inadequacy amongst women with osteoporosis: an international epidemiological investigation. J Intern Med. 2006;260(3):245-254.

29. Haugen J, Ulak M, Chandyo RK, et al. Low prevalence of vitamin D insufficiency among nepalese infants despite high prevalence of vitamin D insufficiency among their mothers. Nutrients. 2016;8(12):825.
International Journal of Women's Health

\section{Publish your work in this journal}

The International Journal of Women's Health is an international, peerreviewed open-access journal publishing original research, reports, editorials, reviews and commentaries on all aspects of women's healthcare including gynecology, obstetrics, and breast cancer. The manuscript management system is completely online and includes

\section{Dovepress}

a very quick and fair peer-review system, which is all easy to use Visit http://www.dovepress.com/testimonials.php to read real quotes from published authors. 